\title{
EL CUERPO Y LA LEY: de la idea de humanidad kantiana a la ética del deseo en Lacan ${ }^{1}$
}

\author{
The body and the law: from the Kantian \\ humanity to the ethics of desire in Lacan
}

\section{Daniel Omar Perez}

Doctor en Filosofía por la Universidade de Campinas (Unicamp). Profesor de la Maestría de Filosofía de la Pontificia Universidade Católica do Paraná (PUCPR). Investigador de CNPq. Miembro de la Sociedade Kant Brasileira. Miembro de la Biblioteca Freudiana de Curitiba, Integra el proyeto Psicanálise, linguagem e cognição (PROCAD 2009-2012 / PUCPR - UFSCar -UFES).Curitiba, PR - Brasil, e-mail: daniel.omar.perez@pq.cnpq.br

\section{Resumen}

El objetivo de este trabajo es mostrar el límite del concepto de humanidad en Kant y el alcance de una ética del deseo con relación a la noción de cuerpo. Primero, presentaremos el concepto de humanidad y su relación con casos encontrados en los textos kantianos. Segundo, evaluaremos su límite en relación con los casos presentados. Tercero, introduciremos los

\footnotetext{
1 Este trabajo contiene elementos de resultados parciales de dos investigaciones que se desarrollan paralelamente en la PUCPR, Brasil. Una es La antropología y la filosofía práctica de Kant, financiada por Cnpq; la otra es El psicoanálisis como experiencia ética, financiada por Fundação Araucaria.
} 
conceptos lacanianos del seminario 7 y 16 para avanzar sobre el límite del concepto kantiano en relación con el problema presentado.

Palabras-clave: Kant. Lacan. Ley. Cuerpo. Humanidad.

\begin{abstract}
The goal of this paper is to show the limit of the concept of humanity in Kant and the reach of the ethics of desire in relation with the notion of body. First, we will show the concept of humanity and the relation with the cases of Kant. Secondly, we will evaluate the limit in relation with the same cases. Thirdly, we will introduce the lacanian concepts of the Seminar 7 and 16 to advance on the limit of the Kantian concept in relation with the problem.
\end{abstract}

Keywords: Kant. Lacan. Law. Body. Humanity.

El cuerpo no hace aparición en lo Real sino como malentendido. Seamos aquí radicales: vuestro cuerpo es el fruto de un linaje y buena parte de vuestras desgracias se deben a que ya nadaba este en el malentendido tanto cuanto podía (LACAN, 1980).

\title{
Los cuerpos de la humanidad
}

La noción de humanidad, entendida como una idea de la razón práctica en sentido kantiano, nos puede servir como el principio de una fundamentación de la declaración de los derechos humanos. Dicho de otro modo, si queremos dar una fundamentación racional por principios a la serie de sentencias que conforman los derechos humanos entonces podemos encontrar en la Idea de humanidad un concepto adecuado para tal fin. Siendo así, podemos decir que los derechos humanos protegerían un cuerpo definido por una ley que ordena tratar a la persona de cada individuo como un fin en sí mismo. Más aún, desde un punto de vista teleológico estamos autorizados a pensar esa persona (en tanto portadora de Humanidad) como el fin último y esto es, entre otras consideraciones, porque se trata de algo capaz de ponerse fines a sí mismo. Retomando, 
por principio un ser humano es un fin en sí mismo que, en principio, es capaz de ponerse fines a sí mismo (KANT, KU, §82 y ss.) ${ }^{2}$.

Así, destacamos del orden de las cosas naturales una cosa que, si bien en un registro está determinada por el principio de causalidad mecánica (como una puerta o una gota de agua), en otro registro puede estar determinada por una idea práctica. Así podemos afirmar que, por un lado, el cuerpo de un ser humano como cosa es objeto de las ciencias que se pautan por el principio de causalidad mecánica, por ejemplo, en las ciencias biomédicas; pero, por otro lado, el cuerpo de un ser humano en tanto destacado por la determinación de una idea práctica puede ser considerado desde el punto de vista de un sujeto autónomo (capaz de decidir sobre sí mismo, sobre la relación con los otros y con las cosas) o bajo la esfera de significación del concepto de sujeto de derecho.

Kant dice que la propia humanidad es una dignidad, pues el hombre no puede ser usado por ningún hombre (ni por otros, ni a rigor por él mismo) apenas como medio, sino que debe siempre y al mismo tiempo ser fin, y en eso consiste su dignidad (su personalidad), por la cual se eleva sobre todos los otros seres mundanos que no son hombres (o seres racionales finitos o seres humanos en general) y así podrían ser usados (KANT, GMS).

Si es aceptable lo que dijimos hasta aquí -aún con ciertas reservas-, desde un punto de vista negativo, estaríamos delante de un concepto que nos permitiría sustentar un derecho racional pautado en la igualdad de limitación de la libertad (KANT, MS, A 33) pero también, y ahora desde un punto de vista positivo, podríamos considerarlo como el punto de partida para la instauración de derechos sobre el uso del cuerpo.

Así, por ejemplo, estaría prohibida la venta de órganos, la comercialización de la sangre y la esclavización en las relaciones de trabajo. Aún cuando el propietario natural de los órganos o de la fuerza de trabajo quiera autorizarlo (como aparentemente sucede en algunos casos que tenemos en Brasil $^{3}$ ) la ley del derecho no podría avalar el contrato sin

2 Los textos de Kant son citados con la sigla correspondiente de la obra en alemán y la página establecida o el §. La nomenclatura es sugerida por Margit Ruffing de la Kant-Forschungsstelle am Philosophischen Seminar der Universität Mainz y aprobada para el uso por la Sociedade Kant Brasileira. Fundamentación de la Metafísica de las costumbres será GMS; Crítica de la razón práctica será KpV; Crítica de la Facultad de Juzgar será KU; Metafísica de las costumbres será MS A la paz perpetua será ZEF.

3 Actualmente -2009- el Ministerio de Trabajo del gobierno federal de Brasil desarrolla un plan para erradicar el trabajo esclavo y cuenta con una comisión de fiscalización móvil que ejecuta operaciones en campo. 
atacar el principio, ya que se trataría de usar el propio cuerpo apenas como medio. De la misma forma podemos pensar en la mutilación o en el canibalismo consentido, como sucedió en Alemania en 20014. Reducir el propio cuerpo a objeto de recorte o a comida es ofrecerlo a la serie de determinaciones causales naturales perdiendo su estatuto de humanidad.

La idea kantiana de humanidad nos permite pensar que alguien puede ser señor de sí mismo pero no su propietario, la relación es de autonomía y no de propiedad, el cuerpo no sería reducido al orden de la propiedad particular (como un terreno o una casa de fin de semana), no se puede disponer del propio cuerpo como cosa, y tampoco disponer del cuerpo de los otros como cosas, puesto que se es responsable por la humanidad en la propia persona y en la del otro.

Pero a pesar de que la legislación parezca tener una idea de humanidad kantiana en su fundamentación, o por lo menos pueda ser pensada en ese sentido, esta idea no siempre es llevada adelante sin conflicto en la interpretación del código. Digo esto porque, por ejemplo, cualquiera de nosotros puede comprar óvulos y esperma en una clínica de reproducción o muestras de ADN de los indios Karitianas de la Amazonia brasileña en un laboratorio de los EEUU (y esto último sin el consentimiento de los indios) $)^{5}$.

\section{El hijo del hombre}

Problemas jurídico-financieros entre seres humanos y laboratorios ya no son excepción entre los casos de los estudios de abogacía, lo que impone un debate académico con consecuencias inmediatas. Una pregunta bastante frecuente en los comités de ética en investigación de las diferentes universidades es: ¿Cuándo tenemos una célula, cuando tenemos un tejido y cuando estamos frente a un ser humano? Dicho en términos prácticos: ¿Cuándo nace un sujeto autónomo, capaz de derecho? Para poder dar cuenta de esa pregunta Kant conceptúa a ese

4 Me refiero a Armin Meiwes, que el 10 de marzo del 2001 mató y comió a Bernd Juergen Brandes después de haberlo conocido por internet y consentido en ser descuartizado y cocinado.

5 El 20 de junio del 2007 el periodista Larry Rohter publicó en el New York Times una nota titulada In the Amazon, giving blood and getting nothing, donde relata la colecta de sangre en la tribu de los karitianas realizada por investigadores de un equipo brasileño y estadounidense y su posterior comercialización en el Coriell Cell Repositories (USA). 
sujeto con el término ciudadano del mundo. El ser humano es un ciudadano del mundo, quiere decir, un fin en sí mismo, capaz de ponerse fines a sí mismo, por lo tanto autónomo y capaz de derecho.

El término ciudadano del mundo, que predica al sujeto de la sentencia ser humano y lo destaca del orden de las cosas naturales aparece en varias oportunidades en la obra de Kant. Pero es en la Metafísica de las costumbres (MS), más específicamente en la Doctrina del derecho $\$ 29$ cuando trata del derecho de los padres y de la adquisición de hijos, que Kant se pregunta: ¿Podemos adquirir hijos como cosas? La respuesta es decididamente negativa para Kant. Si bien la propiedad cumple un papel fundamental en la teoría kantiana del derecho sería una imprudencia hermenéutica considerar que todo se revelaría en la supuesta transparencia del significado de ese concepto. De acuerdo con la perspectiva kantiana podemos adquirir cosas como una mesa de disección o un bisturí, según el derecho de propiedad; podemos adquirir fuerza de trabajo, medida en tiempo o resultado, para producir bienes o servicios por intermedio de otro, de acuerdo con contratos; podemos inclusive adquirir una esposa o esposo y reivindicar la exclusividad en el tratamiento amoroso, según el derecho de matrimonio, pero no podemos adquirir un hijo. A rigor, no existe la adquisición de un hijo en términos kantianos.

De acuerdo con Kant, desde el punto de vista práctico, un hijo es una persona, un ser dotado de libertad y de su producción no podemos hacernos un concepto físico. No se puede definir la noción de persona como la conclusión de una cadena de determinaciones causales naturales que definiría una cierta naturaleza fisiológica. La explicación de un nacimiento desde un punto de vista biológico nunca es condición suficiente para comprender un concepto práctico. Producción de cosas y concepto de persona pertenecen a ámbitos de significación diferentes. En el acto de la procreación acontece un fenómeno de la naturaleza, pero según Kant- también es traída una persona al mundo sin su consentimiento y no apenas como ser mundano sino como un ciudadano del mundo. Ese ciudadano nace libre, pero también nace con el derecho de ser alimentado, protegido y educado para que pueda desarrollarse pragmática y moralmente. Se trata del nacimiento práctico (no-fisiológico) del cuerpo del ciudadano del mundo que genera responsabilidades no-recíprocas a los padres. Quiero decir que lo que el padre adquiere delante del cuerpo del hijo (reconocido en relación con la ley) es una serie de responsabilidades morales y jurídicas que no tienen contrapartida. Podemos decir que este cuerpo del hijo hace 
con que la determinación de los deberes según ley vayan en un sentido, quebrando cualquier tipo de isometría naive. Dicho en otras palabras, la universalidad de la ley toma la forma de los límites del cuerpo que reconoce y define. El cuerpo del hijo requiere de cuidados por parte de los padres que no pueden ser condicionados a cualquier reciprocidad formal o material, estableciendo derechos y deberes desiguales delante de la ley.

\section{La viuda del hombre}

Otro ejemplo de especificidad de la relación del cuerpo con la ley -aún dentro de un pensamiento universalista- nos ofrece Kant en el caso de la viuda. La viuda puede requerir una atención específica por parte de las instituciones del Estado que no es dada igualitariamente a todos los miembros de la sociedad.

A pesar de que Kant deja claro de todos los modos posibles que un gobierno patriótico no es un gobierno paternalista y esto significa literalmente que no puede tratar a sus ciudadanos como a niños (KANT, MS, A 187, B 217 147), quiere decir, no puede tutelar la vida de los individuos ni buscar la felicidad de su pueblo, a no ser corriendo el riesgo de transformarse en populista, no es menos cierto que:

$\mathrm{Al}$ jefe supremo incumbe indirectamente, es decir, como responsable del deber del pueblo, el derecho de gravar a éste con impuestos para su propia conservación (del pueblo), tales como impuestos en interés de los pobres, las inclusas y la iglesia, instituciones llamadas en otro caso de caridad o piadosas (KANT, MS, A 170, B 200).

Está en consonancia con el derecho de un Estado, según Kant, recaudar mediante contribuciones corrientes sobre los ricos para mantener la subsistencia de los pobres, arcar con los gastos de los niños abandonados por causa de la pobreza o la vergüenza y sustentar el establecimiento de hogares para viudas y hospitales (KANT, MS, A 170, B 200 ). Dicho sin ambigüedades ni sutilezas, según Kant, los ricos deben pagar por su riqueza y todos aquellos que por diversos motivos no pueden cargar con su propia subsistencia deben recibir ayuda del Estado. Es un modo de distribución de riqueza necesaria que permite mantener un mínimo de subsistencia como condición material de la dignidad. 
Es una cuestión de derecho público, que se deriva de la unión civil, establecer deberes desiguales y responsabilidades no recíprocas para sustentar la convivencia social. La ley identifica los cuerpos y distribuye los derechos según sus necesidades. La condición de la viuda, el huérfano y el desamparado requiere un tratamiento diferenciado que implica en una legislación específica, no aplicable a otros segmentos de la sociedad. Este modo de responsabilidad del Estado es un derecho en el ejercicio de la ciudadanía. Desde un punto de vista kantiano es aceptable deliberar sobre el modo en el que se implementa el beneficio pero no puede ser admitido discutir su necesidad lógica porque se deriva del propio principio del derecho en su aplicabilidad. Escribe Kant:

El establecimiento benéfico para pobres, inválidos y enfermos, fundado a costa del Estado (fundaciones y hospitales), indudablemente no puede ser abolido. Pero si debe tener preferencia el sentido de la voluntad del testador, y no la letra, pueden muy bien producirse circunstancias que aconsejen eliminar tal fundación, al menos en cuanto a su forma. Así se ha descubierto que el pobre y el enfermo (salvo el enfermo de un hospital de dementes) reciben un cuidado mejor y más barato si se les ayuda entregándoles una determinada suma de dinero (proporcionada a las necesidades de la época), con la que pueden alquilar una habitación donde quieran, con sus parientes o sus conocidos, que si se disponen establecimientos para ello -como el hospital Greenwich-, provistos de un personal costoso, espléndidos, pero que sin embargo limitan en gran medida la libertad. No se puede decir en tal caso que el Estado quite lo suyo al pueblo, legitimado para disfrutar de esta fundación, sino que más bien le favorece al elegir los medios más prudentes para su conservación (KANT, MS, B 178-179).

Está claro que el modo de la implementación de un beneficio no es un mero detalle, -y el fragmento de Kant muestra para que dirección está apuntando la sugerencia de evitar la construcción de casas especiales para acoger personas sin sustento propio. Pero la cuestión que creo que sea fundamental aquí es que el filósofo nos subraya nuevamente la necesidad de mantener un derecho diferenciado, que no le cabe a todos los miembros de la sociedad por igual. Se trata de un derecho que asiste a una comunidad particular. Podríamos pensar aquí en un derecho de minorías que no solo no pierde el carácter universal de la noción de ciudadano sino que lo efectiva en su especificidad. Dicho de otro modo, el estatuto de ciudadano es adquirido 
por los individuos de una sociedad en la medida en que su legislación contribuya para eso. Los miembros de la sociedad racionalmente legislada se separan por segmentos cuyos derechos y deberes son desiguales si consideramos apenas la relación entre los individuos pero no si tenemos en cuenta el principio de la legislación en general.

\section{El hombre extranjero}

Otro caso peculiar es el del extranjero. A pesar de que aún hoy se discuta sobre evolucionismo y creacionismo en los programas de las escuelas primarias y secundarias de algunos países, por lo menos todos sabemos que la Tierra es redonda - o casi - y esta noticia no parece causarnos demasiado espanto. Así, Kant llama la atención sobre la relación entre el formato esférico de la Tierra y "la idea racional de una comunidad universal pacífica, aunque todavía no amistosa" (KANT, MS, A 229, B 259). "La naturaleza - dice Kant - los ha encerrado a todos juntos entre unos límites determinados", en este sentido "todos los pueblos originariamente tienen en común el suelo" y "una comunidad de posible interacción física" (KANT, MS, A 229, B 259). En paralelo, hoy podemos pensar también como una idea racional "una comunidad ecológica universal, aunque todavía no necesariamente ecologista". De la misma forma que Kant advertía sobre las causas y consecuencias de las guerras y las políticas colonialistas que acababan repercutiendo perjudicialmente en todo el planeta, hoy de modo análogo podemos pensar los efectos globales de los cambios en el ecosistema de una determinada región. Escribe Kant:

la frecuentación de las costas, y aún más su colonización para unirlas con la metrópoli, son también ocasiones propicias para que el mal y la violencia de un lugar de nuestro globo se experimenten también en todos los demás. Pero este posible abuso no puede anular el derecho del ciudadano de la tierra a intentar la comunidad con todos y a recorrer con esta intención todas las regiones... (KANT I, MS, A 230, B 260).

Esta reflexión tiene una forma comparable con la que se realiza en la búsqueda de soluciones posibles delante de los problemas ecológicos. Por un lado, encontramos la reivindicación del derecho del individuo que, como ciudadano del mundo, debe poder transitar libremente, comerciar y ejercer sus actividades. Por otro lado, debemos estar atentos a la violación 
de los derechos en cualquier punto de la tierra porque ataca a la idea de humanidad y porque genera consecuencias para todos los otros individuos. La violación de los derechos humanos y la interferencia desmedida en los procesos de la naturaleza van contra las ideas prácticas y repercuten como una onda expansiva en el planeta. Las diferentes formas del colonialismo y el ejercicio ilimitado de la explotación de la naturaleza comparten la misma estructura de funcionamiento. Es por esos motivos justamente que "la idea de un derecho cosmopolita no es un modo fantástico y extravagante de representación del derecho" (KANT, ZEF, BA 46) al igual que no lo sería una ética ecológica global. Al contrario, según Kant es necesario efectivar un derecho cosmopolita porque la tierra les pertenece originariamente a todos los seres racionales finitos y porque sería un modo de combatir el colonialismo. El derecho cosmopolita es un modo de efectivar la idea de humanidad dado que el derecho no se restringe a algun tipo de nacionalismo que circunscribiría el reconocimiento del otro a la pertenencia a un linaje o geografia.

La peculiaridad del derecho cosmopolita es que otorga beneficios a quien no es ciudadano de la república y ni necesariamente ciudadano de uma república cualquiera, sea esta aliada o enemiga. El beneficiario puede ser apenas un ciudadano del mundo, en general, sin república. Sus derechos no se fundamentan en el hecho de ser ciudadano de la república o miembro de una raza sino en la idea de poseedor originario de la superficie de la Tierra. Esto quiebra toda reciprocidad directa y torna desiguales las exigencias. Pero por otro lado, recupera la universalidad del derecho a ser reconocido como ciudadano en cualquier lugar del planeta a un cuerpo reconocido en su relación con una idea práctica.

\section{El alcance del concepto}

Una idea orienta el derecho en Kant: la paz social y perpetua (internacional). Para que pueda ser realizada, quiere decir, para que esta paz se pueda tornar efectiva, es necesario legislar sobre la pose. Por eso es imperioso comenzar por el derecho privado (más específicamente por el derecho de propiedad sobre las cosas). Este es el procedimiento de Kant (1996) en la Metafísica de las costumbres. Siendo así, la tarea de la filosofía trascendental es mostrar las condiciones de posibilidad o condiciones lógico-semánticas de su proposición fundamental (LOPARIC, 2000; 
PEREZ, 2008), a saber: esto es mío (LOPARIC, 2005). De acuerdo con Kant, para que esta frase no sea un mero capricho infantil o una mera quimera y si una sentencia del derecho debe poder estar acompañada de coerción, particularmente de la coerción del Estado: no hay derecho sin fuerza coercitiva del Estado. "Esto es mío" es una proposición que no apenas describe una situación en relación con un objeto, sino que establece una relación con todos los otros sujetos que renunciaron a la pose a favor del declarante. De algún modo, podemos decir que la proposición fundamental del derecho tiene fuerza performativa. Esto funciona no solo en el derecho sobre las cosas sino también en el derecho sobre el arbitrio de los otros y el derecho público. Siendo así, la proposición fundamental sustentada en la coerción del Estado pone en práctica el principio fundamental que dice: una acción es conforme a derecho cuando permite, o cuya máxima permite a la libertad del arbitrio de cada uno coexistir con la libertad de todos según una ley universal (KANT, MS, A B 33). De este modo y de acuerdo con los casos presentados arriba podemos pensar que la legislación no necesariamente restringe o habilita indistintamente sino en función del ejercicio coexistente de la libertad de todos. Por eso el Estado no solo puede sancionar obstaculizando a quien obstaculiza la libertad de los otros sino también crear normas que favorezcan la coexistencia de los individuos dividiendo la legislación sobre la sociedad en segmentos con peculiaridades, beneficios y exigencias diferentes y divergentes. Dicho en otras palabras, lo que está en juego no es que todos tengan la misma responsabilidad material o materialmente enunciada, sino que, en principio, todos tengan la misma responsabilidad delante del enunciado formal acerca de la coexistencia de la libertad de todos.

El individuo participa de los derechos del ejercicio de su libertad en el Estado también por medio del segmento al cual pertenece. Y esta pertenencia está marcada por una cierta naturaleza humana, no meramente fisiológica, que se define por los contornos del cuerpo del individuo en relación con la ley. Si hegelianamente podemos decir que un individuo solo puede participar de la humanidad universal por medio de la identificación con el Estado de una nación, y así se es humano (como universal) porque se es brasileño o alemán (como particular); así, hablando en términos prácticos todos ejercen coexistentemente su libertad desde que cada uno pueda tener acceso a lo que es suyo. Como este "suyo" no es una relación directa o natural con la cosa, sino que se establece por una relación con todos los otros individuos bajo una ley, entonces es posible 
realizar esa ley otorgando derechos a los individuos de determinadas minorías y comunidades e imponiendo obligaciones a los individuos de otros sectores sociales concretos. Estos mecanismos permitirían avanzar en los productos del Estado de Derecho y así también mostrar un progreso de la especie humana que marcaría una tendencia hacia lo mejor. Se trataría de un progreso de la historia humana (sobre la cual Kant escribe en Conflicto de las facultades que no solo mostraría elementos políticos y de derecho sino que también contribuiría para que los individuos deban poder actuar por deber moral (aunque no necesariamente).

\section{El matrimonio del hombre}

Hasta aquí podemos ver como casos particulares y problemáticos de la relación de los cuerpos con la ley pueden ser resignificados e articulados con conceptos no menos problemáticos en el ámbito de los derechos. Dicho todo esto me permitiré ahora pentrar en el último ejemplo para tratar la relación entre el cuerpo y la ley por medio de la pregunta: ¿qué es un matrimonio?

De acuerdo con Kant, en la Doctrina del derecho, la unión sexual o comercium sexuale es el uso que un ser humano hace de los órganos y las capacidades sexuales del otro (usus membrorum et facultatum sexualium alterius). Kant es muy preciso en su clasificación y nos enseña que la unión sexual puede ser realizada entre animales y personas, personas del mismo sexo y entre personas de sexo diferente. No entraré en detalles en los dos primeros casos, apenas consideraré el tercero. Por un lado, la unión sexual entre personas de diferente sexo puede ser entendida como vaga libido, venus volgivaga o simplemente fornicatio y, por otro lado, como matrimonio.

El primer modo (fornicatio) puede ser entendido como una relación animal, no apenas porque el evento puede ser provisto de algún tipo de fogosidad accidental sino también por su fin determinado en el tiempo. Como vaga libido la relación entre las personas es circunstancial, sin querer otro vínculo. Aún dentro de este grupo la unión puede ser comprendida por medio de un contrato temporario. En el pactum fornicationis Kant nos enseña que, por medio de algún tipo de pago, podemos contratar ocasionalmente a una persona como objeto de goce. Aunque no sea necesario, en este caso la reciprocidad del goce no es una exigencia. Lo que acabo de describir en términos kantianos se conoce 
popularmente como prostitución y, como todos sabemos, Kant condena su práctica por reducir a una persona a objeto de goce del otro, quiere decir, la prostitución trata al otro apenas como medio. Decididamente, la ley impone un límite al goce.

Aparentemente, cuando la unión se establece según leyes duraderas y tenemos un matrimonio la situación sería diferente. La pregunta que se impone aquí es: ¿En qué consisten estas leyes del matrimonio? ¿Qué es un matrimonio? Según Kant, el contrato matrimonial no se define ni por la procreación ni por el amor, sino por el goce recíproco y exclusivo de los órganos y capacidades sexuales. Mientras el contrato de prostitución no exige reciprocidad y puede ser limitado en el tiempo, el contrato matrimonial garantiza (al menos de derecho) la reciprocidad del goce y no puede ser a priori limitado en el tiempo. Hacemos contratos matrimoniales en los cuales podemos compartir o no total o parcialmente la propiedad de los bienes materiales, tenemos matrimonios que deciden también compartir o no el nombre, pero no podemos hacer un contrato matrimonial en el que, por ejemplo, nos reservamos el derecho de usar nuestros órganos genitales una o dos veces por semana con una compañera o compañero eventual o dando término al contrato en, por ejemplo, 36 meses. Es esto lo que significa el matrimonio como una unión de dos personas por la pose y el goce sexual recíproco y exclusivo.

En el acto del contrato matrimonial el sujeto se torna objeto de goce para el otro indefinidamente y no apenas temporariamente (como en una relación de prostitución). Esta es la cuestión más importante del matrimonio: el otro se torna objeto de goce para mí a condición de que yo también me torne objeto de goce para el otro. Esto coloca al matrimonio como una relación de goce bajo la ley del derecho donde yo adquiero un objeto de goce pero a la vez busco ser adquirido como objeto de goce. Doy mi consentimiento para ser reducido a medio. Es una exigencia del contrato (y de la legislación vigente) que haya una reducción a objeto de goce para que el matrimonio funcione según las leyes del derecho.

Tal vez este sea uno de los momentos más lúcidos de Kant ya que para abordar la cuestión descarta de salida cualquier tipo de idilio romántico ingenuo o de necesidad biológica de perpetuar la especie. Pero esta posición nos coloca en un impasse que ya no es tan fácil de resolver, ni aún con restricciones, como en los casos anteriores.

En la legislación brasileña existían casos donde el casamiento podía ser una forma de extinguir la pena por violación sexual. Si el violador 
aceptaba casarse el hecho era considerado como un modo de reparación moral y jurídico al daño causado a la víctima. En esos casos se supone que se pasa de un acto de reducción a objeto de goce no consentido al restablecimiento de la dignidad que proporcionaría el nombre y la protección que ofrecería el casamiento. En el otro extremo, actualmente algunos integrantes de la Ordem dos Advogados do Brasil de São Paulo debaten sobre la posibilidad de la pena de castración como una forma eficaz de reducir el crimen de reducción a objeto de goce no consentido. Ya dentro de la figura del matrimonio, hasta la década de 1980 no se consideraba posible aplicar la figura de la violación sexual. Se suponía que el contrato matrimonial obligaba a comparecer sexualmente, por lo tanto la mujer no podía negarse a entregar sus órganos al goce de su compañero. En los Comentarios a la ley de crímenes hediondos publicado por Sznick (1993) se argumenta de la siguiente forma:

La negativa de la mujer solamente está fundamentada cuando ella está embarazada de ocho o nueve meses, o en el caso de una enfermedad grave. En ningún otro caso. Verdad es que al hombre no le es lícito usar la fuerza, pero dentro del casamiento la recusa inmotivada puede llevarlo a usar de ciertos métodos con moderación (SZNICK, 1993, p. 60).

Hoy ningún juez en Brasil escribiría algo parecido en una sentencia sin arriesgarse a un escándalo público, lo que no significa que a algunas personas no les guste correr riesgos. Pero en general se entiende que la mujer en el matrimonio antes de honrar el deber de comparecer sexualmente tiene el derecho reconocido de autonomía sobre el propio cuerpo restituyéndose así la idea de humanidad como principio de fundamentación. Esto apenas contribuye a fortalecer una sentencia pero de ningún modo resuelve el conflicto planteado.

\section{La ley y los cuerpos en la relación sexual}

Siendo así, hay una pregunta que se impone: ¿hasta donde es posible legislar sobre las relaciones sexuales considerando la idea de humanidad en la relación? Dicho en otras palabras: ¿es posible considerar la humanidad en una relación de goce sexual? Si por un lado, la noción de humanidad y de persona como un fin en sí mismo nos torna sujetos, con 
todo lo que esto implica para los derechos del uso del propio cuerpo, por otro lado, parece difícil pensar en la posibilidad del acto sexual entre dos personas que representan a toda la humanidad en sí mismas. Cuando consideramos la humanidad parece que estamos eliminando cualquier posibilidad de goce sexual, cuando no la consideramos hacemos una reducción a objeto. Si reconocemos la reciprocidad en la relación de goce matrimonial entonces también deberíamos reconocer la reciprocidad (mediante pago) en la prostitución, como de hecho y derecho se hace con cualquier otro contrato de trabajo o prestación de servicios. Así, podríamos promover tanto el trabajo y la prostitución como el casamiento bajo la ley del derecho como un uso del cuerpo. Pero por esa vía el problema se complica aún más en la perspectiva de una legislación por principios.

\section{Un cambio de perspectiva para tratar el cuerpo y la ley: el deseo}

La relación entre la ley y el cuerpo, como vimos hasta ahora, tiene desdoblamientos sugestivos. Pero hay una conclusión provisoria que podemos destacar a esta altura. En un determinado sentido podemos decir que:

El goce implica el mal del prójimo. La ley impone la renuncia al goce. Sirve a la economía de los intercambios simbólicos, intercambios regulados por una ley que asegura un placer menor, más cierto, más seguro, más útil, al precio de una traición fundamental al goce propio (SANTOS, 1995, p. 121-122).

Más aún, la regulación de la ley puede permitir el reconocimiento de los derechos del cuerpo y también su anulación. Ya no es poco común encontrar trabajos que proponen profundizar la interpretación que se orienta por la hipótesis que declara haber una línea directa entre el formalismo kantiano y la maquinaria de Auschwitz o, dicho de otro modo, que los campos de concentración como funcionamiento neutro no son sino el resultado necesario de la Ilustrada autonomía de la Razón. Sin desconocer la contribución indiscutiblemente preciosa para la filosofía y las ciencias sociales y humanas que tienen esas investigaciones, podemos advertir que la estructura formal de ese tipo de hipótesis es la misma que afirma que el Gulag ya está Marx o que el exterminio y las cosechadoras ya están contenidas en el día que Prometeo le robó el fuego 
a Zeus. Para evitar una escatología busqué presentar el alcance y el límite del conflicto hasta su imposibilidad de resolución.

Comúnmente se lo acusa a Kant de haber cometido la insensatez de descuidar la materialidad de las circunstancias a favor de un formalismo universal que comete la negligencia de no atender a la especificidad de cada acto, lo que se comprueba decididamente falso si nuestra lectura de la filosofía práctica kantiana no para en el §7 de la Crítica de la razón práctica. Su límite está menos en los descuidos que en la formulación de los propios conceptos. La cuestión del goce sexual con la que se encuentra Kant produce un corto-circuito en el modo con que se opera con los acontecimientos a partir de los conceptos kantianos, nos presenta un gap que lejos de dar las pistas para su resolución se tensiona.

La relación entre goce y ley se nos presenta en términos antinómicos. Esto significa que su resolución no puede ser encontrada en los términos de una síntesis superadora, es preciso afirmar los dos términos del conflicto manteniendo la tensión. Pero para eso precisamos avanzar por el gap que nos propicia la antinomia utilizando un nuevo orden categorial. Es sobre la base de esa imposibilidad que considero que Lacan avanza a partir de lo que propone desde el Seminario 7, pero para pensar ya no una ética del deber o del goce y si del deseo. Así, como escribe Joan Copjec "antes que renunciar al formalismo de Kant, Lacan apunta aquí a revitalizarlo" (COPJEC, 2006, p. 12). El criterio del acto ético ya no residiría en el examen exhaustivo de las propias particularidades del evento hasta encontrar allí su propio padrón ni en la obediencia de la ley por deber, sino que, más allá de la ley, consistiría en seguir el propio deseo. Seguirlo inclusive kantianamente en el sentido en que no puede haber cualquier motivación o estímulo patológico. En efecto, el deseo para el psicoanálisis no es ni apenas un fenómeno natural del cuerpo, ni una determinación que se guía estrictamente por representaciones mentales. En una ética del deseo el cuerpo se relaciona consigo mismo y con otros cuerpos según una lógica que no es la del derecho y tampoco la de la biología.

La máxima que posiciona al sujeto en relación con el deseo no puede ser relativizada y su ejecución puede ser entendida observando lo dicho acerca de la diferencia que Freud establece en Tres ensayos para una teoría sexual entre fijación (Fixierabeit) y perseverancia (Haftarkeit). La relación del sujeto con el objeto no es fija (establecida a priori o por la naturaleza) pero tampoco es indistinta y sus modos tampoco lo son. 


\section{¿Cuál es entonces la ética de la relación del cuerpo consigo mismo y con los otros cuerpos según una ética del deseo?}

Debe notarse que la pregunta no demanda un que hacer con el cuerpo y sus relaciones, como si la ética del deseo fuese una teoría de la acción o un código de conducta. Una demanda de ese tipo supondría la posibilidad de adecuación a priori entre verdad y acción humana. No es el caso. En 1945, en El Tiempo Lógico Lacan (1998a) nos presenta a los tres personajes de un cuento donde si ellos no actúan no pueden conocer la verdad y entonces deben actuar para poder descubrirla. No pueden tener la certeza del próximo paso si no lo ejecutan. La cuestión es anticipar la acción sin saber la verdad para así descubrirla. Es en la incertidumbre del acto que se manifiesta la verdad del sujeto. Es una ética del acto y no del suministro de reglas más o menos confiables, quiere decir, previsibles. Veamos cómo esta paradoja dice respecto de la ética del deseo.

"Nuestra experiencia [la experiencia analítica] -dice Lacan- nos condujo a profundizar más de lo que jamás fue hecho antes de nosotros, el universo de la falta" (LACAN, 1997, p. 10). La indicativa de Lacan sobre esa falta refiere al asesinato del padre e al instinto de muerte en Freud. La falta se articularia en el instante mítico del origen de la ley y de un devenir muerte. Sería esa falta la que acogería la posibilidad de la acción humana. Debe notarse que no se trata de la falta de alguna cosa específica que viene a completar un ideal, sino de una falta constitutiva que da lugar inclusive a la tentativa de construcción de un ideal que busque sanar la falta.

De acuerdo con Lacan, "la experiencia moral" coloca al hombre en relación a una dirección o tendencia, engendrando un ideal de conducta. La dimensión ética en el psicoanálisis se sitúa más allá del mandamiento, más allá del sentimiento de obligación y descortina el sentimiento de culpa (LACAN, 1997, p. 11). Y como para el psicoanálisis no hay culpa sin deseo podemos aún avanzar más y decir que "la génesis de la dimensión moral no se enraíza en otro lugar sino en el propio deseo. Es de la energía del deseo que se desprende la instancia de lo que se presentará en el término de su elaboración como censura" (LACAN, 1997, p. 12). La experiencia del obsesivo, por ejemplo, se estructura en el inicio para saber que el enigma en torno del deber como tal ya está siempre formulado (LACAN, 1997, p. 17) eso hace posible el establecimiento de un ideal en relación con el deber como elemento secundario. Actuar por deber se transforma en un bien y el problema de la ética se puede pensar, 
en cierta medida, como el problema de los bienes que son colocados o perseguidos para configurar el ideal. El mismo Lacan nos recuerda como en Aristóteles, por ejemplo, encontramos el problema del Bien Supremo, en el utilitarismo encontramos el problema del Bien Común, y entre un extremo y otro de la historia encontramos una gama de bienes a ser alcanzados según diferentes modos.

Así, el psicoanálisis nos permite localizar la reflexión del origen de la moral en una noción de culpa asociada a la emergencia del deseo en el proceso de recalque. Ese dispositivo nos posibilita comprender el fenómeno de la civilización y de la cultura (LACAN, 1997, p. 15) y también el de la moral.

Ahora bien, de acuerdo con Lacan "la cuestión ética" en psicoanálisis "se articula por medio de una orientación del hombre en relación a lo real" (LACAN, 1997, p. 21). Para Lacan "La ley moral, el mandamiento moral, la presencia de la instancia moral, es aquello por medio de lo cual, en nuestra actividad en cuanto estructurada por lo simbólico, se torna presente lo real - lo real como tal, el peso de lo real" (LACAN, 1997 7, p. 31). Para alguien que no está familiarizado con los conceptos lacanianos la cita anterior puede parecer enigmática y efectivamente lo es. ¿Cómo es que la ley moral es aquello por medio de lo cual se torna presente lo real y no como su expresión o emergencia? De acuerdo con Lacan, "lo real se inscribe primero en términos de defensa. Defensa que ya existe antes de que las condiciones de recalque como tal se formulen" (LACAN, 1997, p. 43). Pero una condición aún anterior es notada en la lectura lacaniana del Proyecto de Freud, para elucidar este punto clave me permito hacer una extensa cita (LACAN, 1997, p. 69-70):

El Ding como Fremde, extraño y aún pudiendo ser hostil en un determinado momento, en todo caso como lo primero exterior, es en torno de lo que se orienta todo el encaminamiento del sujeto. Es sin duda alguna un encaminamiento de control, de referencia en relación a qué? - al mundo de sus deseos. Él hace la prueba de que alguna cosa, al final, se encuentra justamente allí, que en un cierto punto puede servir. ¿Servir a qué? - a nada más que a referenciar, en relación a ese mundo de ansias y de espera orientado en dirección a lo que servirá, cuando sea el caso, para alcanzar das Ding. Ese objeto estará allí cuando todas las condiciones fueren alcanzadas, al final de cuentas - evidentemente, es claro que lo que se trata de encontrar no puede ser reencontrado. Es por su naturaleza que el objeto es perdido como tal. Jamás será encontrado. Alguna cosa está allí esperando algo mejor, o esperando algo peor, pero esperando. 
El mundo freudiano, o sea, el de nuestra experiencia comporta que ese es el objeto, das Ding, en cuanto lo Otro absoluto del sujeto, lo que se trata de reencontrar.

lo que es buscado es el objeto en relación al cual el principio de placer funciona. Ese funcionamiento es, en el tejido, en la trama, el soporte a que se refiere toda la experiencia práctica (LACAN, 1997, p. 70).

En efecto, a partir de estos fragmentos de Lacan podemos decir que el sujeto se dirige, a su modo, a la Cosa (das Ding). El modo es fundamental para las acciones del sujeto, uno de ellos es la insatisfacción, el otro un exceso. La Cosa funciona como vacío originario, lo que permite el movimiento de la acción. Das Ding es lo real que comanda, que ordena, a partir o entorno de lo cual se organiza alguna cosa. (LACAN, 1997, p. 72).

Das Ding es originalmente lo que llamamos fuera de significado. Es en función de ese fuera-de-significado y de una relación patética a él que el sujeto conserva su distancia y se constituye en un mundo de relación, de afecto primario, anterior a todo recalque. Es con relación a das Ding que es hecha la elección de neurosis (LACAN, 1997, p. 71-72).

La conducta de la histérica, por ejemplo, tiene como objetivo recrear un estado centrado por el objeto, en la medida en que ese objeto, das Ding, es, como Freud escribe en algún lugar, el soporte de una aversión. Es en la medida en que el objeto primero es objeto de insatisfacción que el Erlebnis específico de la histérica se ordena.

En oposición -la distinción es de Freud y no hay motivos para ser abandonada- en la neurosis obsesiva el objeto en relación al cual la experiencia de fondo se organiza, la experiencia de placer, es un objeto que, literalmente, trae placer demás" (LACAN, 1997, p. 70).

Por lo tanto, considerando entonces la posición de das Ding entendemos en qué sentido Lacan afirma que: "Contrariamente a lo que es admitido, creo que la oposición entre el principio de placer y el principio de realidad, la del proceso primario y del proceso secundario sean menos del orden de la psicología que del orden de la propia experiencia ética". Así, "el conflicto es, vamos a decirlo, masivamente del orden de lo moral" (LACAN, 1997, p. 49). Más aún, Lacan afirma en el Seminario 11 que el estatuto del Inconsciente es ético (LACAN, 1998b, p. 37). Lo que nos hace pensar que Lacan está evitando cualquier tipo de mentalismo psicologista para resolver la cuestión. Su interpretación del Proyecto de una psicología se orienta en ese sentido. Dice Lacan: 
Das Ding es lo que - en el punto inicial, lógicamente, y del mismo modo, cronológicamente, de la organización del mundo en el psiquismo- se presenta, y se aisla, como el término extraño en torno de lo cual gira todo el movimiento de la Vorstellung, que Freud nos muestra gobernado por un principio regulador, el principio del placer, vinculado al funcionamiento del aparato neurónico. Es en torno de ese das Ding que rueda todo ese proceso adaptativo, tan particular en el hombre visto que el proceso simbólico se muestre allí inextricablemente tramado (LACAN, 1997, p.76).

Para Lacan el problema fundamental del Proyecto también es ético y no fisiológico. Las Vorstellungen, ordenadas por el principio de placer, se modulan con las leyes más fundamentales del funcionamiento de la cadena significante (metáfora y metonimia) (LACAN, 1997, p.80-81). "Lo bueno y lo malo entran desde luego en el orden de la Vorstellung, están allí como índices de lo que orienta la posición del sujeto, según el principio de placer..." "La acción moral, en efecto, se injertó en lo real. Ella introduce en lo real la novedad, creando allí un surco donde el punto de nuestra presencia es sancionado" (LACAN, 1997, p. 32). "En la experiencia analítica buscamos una verdad, pero esa verdad no es otra que el verdadero Wunsch. Ese "Wunsch no tiene el carácter de una ley universal, sino, al contrario, de una ley particular - aún cuando sea universal que esa particularidad se encuentre en cada uno de los seres humanos" (LACAN, 1997, p. 35). Así pasamos de la Cosa a las cosas u objetos de deseo. De ese modo se establece el movimiento fundamental en la relación con los objetos. Otra cosa surge en lugar del goce (absoluto, imposible). Lacan dice que se trata de entidades evanescentes (seno, mierda, voz, mirada, [...]). Serian fabricaciones de la renuncia al goce articuladas en torno de la fantasía. En torno de ellas podrían producirse lo que se denomina plus-degoce. Dicho sin ambigüedades: ese plus o mínimum de goce se diferencia del goce porque el sujeto se articula en una relación diferente con el vacio que lo habita. Siendo así, no hay nada delante del sujeto, sino él mismo y la relación que se establece no sería sino con el propio vacío (LACAN, 2008, p. 21 e ss.).

Para Lacan es a partir de la creencia en el Otro que el sujeto "produce su consistencia y su ingenua confianza en que él es como yo" (LACAN, 2008, p. 24). Este no sería sino un modo de comprehender la igualdad delante de la ley. Un modo incrédulo que sustenta en la supuesta garantía del Otro (la ley), la igualdad con el otro (mi semejante). Es por esa vía y únicamente por ella que podemos llegar al impase imaginario de una relación como la que reconstruimos en el caso del matrimonio kantiano. 
Ciertamente, el sujeto se constituye como tal a partir del Otro y lo que resta como efecto de constitución es lo que denominamos con Lacan objeto $a$, especie de pedazo caído, perdido y buscado en la medida en que se inscribe como demanda que se realiza al Otro. Pero eso funciona así justamente por la inexistencia del Otro. El Otro no existe y en eso reside su eficacia pero también su límite. A rigor, lo que hay son goces, que son siempre del cuerpo. De acuerdo con Lacan la pulsión sale de la fuente, bordea sin tocar el objeto y retorna al propio sujeto. Este movimiento de la pulsión muestra que no se trata de un acople entre dos para hacer uno. La idea moderna de relación entre sujeto-objeto aquí no se sustenta. Es por eso que Lacan no hablará de aprehensión del objeto y sí de goce o, para ser más específico, de goces.

\section{CONCLUSIÓN}

Con Kant podemos avanzar sobre la relación entre la ley y el cuerpo hasta donde se reconoce el propio límite de la razón humana. Quiere decir, hasta donde lo permite la idea de humanidad. Una idea de la razón que en la misma medida que permite reconocer un fin final en el hombre también nos coloca delante de un problema cuando se trata de legislar sobre las relaciones sexuales de ese mismo hombre. Con Lacan avanzamos sobre el límite que Kant propone. Pasando de una ética del deber a una ética del deseo la cuestión de la relación de la ley con el cuerpo se reformula. Así, el psicoanálisis coloca al sujeto delante de su propio goce. "Su praxis [la del psicoanálisis] no es sino preludio a la acción moral como tal - dicha acción siendo aquella por la cual desembocamos en lo real" (LACAN, 1997, p. 32).

\section{REFERENCIAS}

COPJEC, J. Imaginemos que la mujer no existe: ética y sublimación. BsAs: FCE, 2006a.

El sexo y la eutanasia de la razón. Buenos Aires: Paidós, 2006b.

KANT, I. Kants gesammelte Schriften. Berlin: Walter de Gruyter, 1902. 
Crítica de la facultad de juzgar. Caracas: Monte Ávila, 1992. La metafísica de las costumbres. Barcelona: Ediciones Altaya, 1996.

LACAN, J. O Seminário 7. Rio de Janeiro: Jorge Zahar, 1997.

. O tempo lógico. In: LACAN, J. Escritos. Rio de Janeiro: Jorge Zahar, 1998a. p. 197-213.

O Seminário 11. Rio de Janeiro: Jorge Zahar, 1998b.

O Seminário 16. Rio de Janeiro: Jorge Zahar, 2008.

LOPARIC, Z. A semântica transcendental de Kant. Campinas:Ed. da Unicamp, 2000 .

O problema fundamental da semântica jurídica de Kant. In: PEREZ, D. O. (Org.). Kant no Brasil. São Paulo: Escuta, 2005. p. 273-313.

PEREZ, D. O. Kant e o problema da significação. Curitiba: Champagnat, 2008.

ROHTER, L. In the Amazon, giving blood and getting nothing. New York: The New York Times, 2007.

SANTOS, T C. dos. Fundamentos da direção da cura psicanalítica: da angustia ao desejo na clínica da histeria e da neurosse obsessiva. Cadernos do Tempo Psicanalítico, Rio de Janeiro, n. 1, p. 121-132, 1995.

SZNICK, V. Comentários à lei dos crimes hediondos. 3. ed. São Paulo: Ed. Universitária de Direito, 1993.

Recibido: $10 / 12 / 2008$

Received: $12 / 10 / 2008$

Aprobado: 04/03/2009

Approved: 03/04/2009 